\title{
Erratum to: Hypomagnesemia and increased risk of new-onset diabetes mellitus after transplantation in pediatric renal transplant recipients
}

\author{
Wesley Hayes $^{1,2} \cdot$ Sheila Boyle $^{1}$ - Adrian Carroll ${ }^{1}$ - Detlef Bockenhauer ${ }^{1,2}$. \\ Stephen D. Marks ${ }^{1,2}$
}

Published online: 9 February 2017

(C) IPNA 2017

\section{Erratum to: Pediatr Nephrol}

DOI 10.1007/s00467-016-3571-6

The last sentence of the second paragraph of the Results section should read:

Fourteen patients developed NODAT between 8 and 30 days post transplantation, five of whom required insulin therapy for $>12$ months.

The authors apologize for this error and for any inconvenience caused.

\footnotetext{
Wesley Hayes

Wesley.hayes@gosh.nhs.uk

1 Great Ormond Street Hospital for Children, London WC1N 3JH, UK

2 University College London Institute of Child Health, London, UK
} 